ISSN 0819-2642

ISBN 0734025742

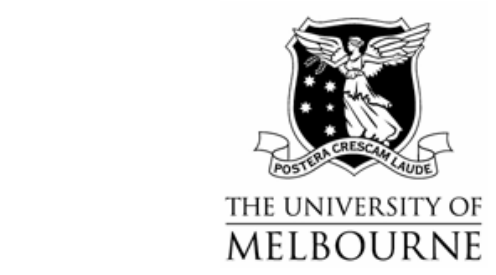

THE UNIVERSITY OF MELBOURNE

DEPARTMENT OF ECONOMICS

RESEARCH PAPER NUMBER 918

SEPTEMBER 2004

\title{
AN EXPERIMENTAL STUDY OF COMPLIANCE AND LEVERAGE IN AUDITING AND REGULATORY ENFORCEMENT
}

by

Timothy N. Cason

$\&$

Lata Gangadharan

Department of Economics

The University of Melbourne

Melbourne Victoria 3010

Australia. 


\title{
An Experimental Study of Compliance and Leverage in Auditing and Regulatory
}

\author{
Enforcement* \\ Timothy N. Cason \\ Purdue University \\ and \\ Lata Gangadharan \\ University of Melbourne
}

September 2004

\begin{abstract}
Evidence suggests that a large majority of firms and individuals comply with regulations and tax laws even though the frequency of inspections and audits is often low. Moreover, fines for noncompliance are also typically low when regulatory violations are discovered. These observations are not consistent with static compliance models. Harrington (1988) modified these static models by specifying a dynamic game in which some agents have an incentive to comply even when the cost of compliance each period is greater than the expected penalty. This paper reports a laboratory experiment based on the Harrington model framework, in which subjects move between two inspection groups that differ in the probability of inspection and severity of fine. Subjects decide to comply or not in the presence of low, medium or high compliance costs. Enforcement leverage arises in the Harrington model from movement between the inspection groups based on previous observed compliance and noncompliance. Our results indicate that consistent with the model, violation rates increase when compliance costs become higher and as the probability of switching groups becomes lower. Behavior does not change as sharply as the model predicts, however, since violation rates do not jump from 0 to 1 as parameters vary across critical thresholds. A simple model of bounded rationality explains these deviations from optimal behavior.
\end{abstract}

JEL Classification: C91, Q20, Q28

Key Words: Regulatory Compliance, Laboratory Experiments, Tax.

\footnotetext{
* Timothy N. Cason: Department of Economics, Krannert School of Management, 100 S. Grant Street, Purdue University, West Lafayette, IN 47907-2076, USA. Email: cason@mgmt.purdue.edu. Lata Gangadharan: Department of Economics, University of Melbourne, Vic 3010, Australia. Email: latag@unimelb.edu.au. We thank Ashraf Al Zaman for valuable research assistance. For helpful comments we also thank, without implicating, seminar and conference participants at the Public Choice Meetings/ESA Meetings, and McMaster, Purdue and Lakehead Universities. This research has been supported by a grant from the U.S. Environmental Protection Agency's National Center for Environmental Research (NCER) Science to Achieve Results (STAR) program. Although the research described in the article has been funded in part through EPA grant number R829609, it has not been subjected to any EPA review and therefore does not necessarily reflect the views of the Agency, and no official endorsement should be inferred.
} 


\section{1: Introduction}

Regulatory policy makers have observed that many firms and individuals comply with regulations even when both the frequency of audits and the penalty for violations are low. This is seen in areas as diverse as income tax collection, customs, antitrust laws, health and safety and environmental regulation. This phenomenon is difficult to explain using static enforcement models (for example, Linder and McCabe, 1984, Storey and McCabe, 1980, Harford, 1978) in which the penalty facing the firm depends only on the firm's performance in the current period and not on its previous compliance record.

Economists in recent years have proposed dynamic repeated game models to reconcile the low expected penalties and yet high observed compliance rates. In these models, the regulated firm and the enforcement agency can react to previous actions by the other (Landsberger and Meilijson, 1982, Greenberg, 1984, Harrington, 1988). The enforcement agency alters the expected penalty and the inspection frequency based on the firm's past performance. Harrington finds that a firm could have an incentive to comply with regulations even though the costs of compliance in individual periods exceed the expected penalty for violation. This is important in practice because political or practical considerations often limit the size of the fine that can be imposed on a firm. For example, in many states there is a restriction on the size of penalties that can be levied for violating an environmental regulation (e.g., $\$ 5000$ per day). ${ }^{1}$

The strategy the enforcement agency uses to achieve this result divides the firms into two groups, and the firms in one group face a more severe enforcement regime than the firms in the

\footnotetext{
${ }^{1}$ Compliance can occur for other reasons, of course. Firms may sometimes comply with regulations to guide regulatory authorities to set higher standards for the whole industry, thereby increasing the costs of their rivals (Salop and Scheffman, 1983). Firms could also comply to obtain a reputation of being an environmentally conscious organization. Arora and Gangopadhyay (1995) show that public recognition plays a very important role in the success of voluntary environmental programs. Individuals and firms could also comply with regulations because they are honest and get disutility from violating regulations.
} 
other group. A firm's compliance status determines which group it is in. Each firm can move from one group to the other depending on its performance. Violations discovered in the rarely inspected "good" group are punished by transfer into the more frequently inspected "bad" group and compliance discovered in the more frequently inspected group is rewarded with the chance of a return to the rarely inspected good group. This enforcement scheme poses a Markov decision problem from the firm's perspective. The firm moves from group to group according to transition probabilities that depend not only on the inspection probabilities and the current state of the system but also on the action taken (comply or not) during that period. Harrington shows that firms' optimal policies in this scheme depend upon their individual costs of compliance. Low cost firms are always in compliance, high cost firms are never in compliance and medium cost firms move in and out of compliance depending on the results of recent inspections.

This paper reports laboratory evidence on compliance behavior of decision makers when faced with enforcement conditions consistent with the Harrington model framework. We examine treatments in which the compliance costs are low, medium or high. In these within session treatments we also change the probability of the firm switching from the frequently inspected group to the rarely inspected group if inspected and found compliant, from 10 percent to 90 percent. Our results indicate that consistent with theoretical predictions, violation rates increase when compliance costs become higher and as the probability of switching groups becomes lower. Behavior does not change as sharply as the model predicts, however, since violation rates do not jump from 0 to 1 as parameters vary across critical thresholds. A simple model of bounded rationality, in which agents choose more profitable strategies with higher probability but not with probability one, can explain these deviations from optimal behavior.

Although these conditional audit rules have received significant attention in the 
theoretical literature, direct empirical evidence on their performance is scarce. Empirical research using field data exists (e.g., Helland, 1998, Oljaca et al., 1998, Eckert, 2004), but it is hampered by the absence of reliable information regarding individual reporting behavior and unknown compliance decisions for uninspected firms. ${ }^{2}$ Laboratory experiments, however, are well suited to study the different features of compliance schemes and individual behavior within these schemes. Most of the existing experimental literature on compliance and auditing has focused on static models, where different policy changes like an increase in tax rate, a change in penalty rates, tax amnesties or changes in audit probabilities are introduced to determine the impact on compliance behavior. Alm and McKee (1998) provide a survey of this literature. Torgler (2002) surveys the experimental findings on the tax compliance literature with a focus on social norms and institutional factors, which are seen to encourage compliance.

Alm, Cronshaw and McKee (1993) examine dynamic audit rules and compare these to a 5 percent inspection probability random audit rule. The auditor's discovery of non-compliant behavior in a random audit scheme could lead to audits of previous or future years with certainty. Alm et al. find that the forward looking rules achieve lower compliance rates, since in this scheme an individual can cheat until audited in the current period and can then avoid any additional penalties by reporting honestly for the next two periods. On the other hand, under the backward looking audit policy, an individual found to be non-compliant in the current period has no chance of avoiding penalties on previous periods' records. This increases the incentive for individuals to comply under backward looking policies and might be more attractive from the viewpoint of regulators, particularly in the area of tax reporting. Backward looking schemes

\footnotetext{
${ }^{2}$ Helland (1998) uses data from the American pulp and paper industry to test whether environmental regulators audit and fine according to the model described in Harrington (1988). He finds that firms who are discovered in violation experience a one or two quarter penalty period during which they are inspected more frequently. Eckert's (2004) data on Canadian petroleum storage facilities is also consistent with the Harrington framework. She finds that inspections deter future violations, although the effect is small.
} 
however would typically not be feasible in others kinds of regulatory areas like environmental and natural resource management when the data (for example, for actual emissions rates) from previous periods cannot be checked. Therefore, forward-looking conditional audit rules like those studied here are practical for a wider range of applications.

The previous research most closely related to the present study is Clark, Friesen and Muller (2004), which compares two dynamic audit rules: Harrington's (1988) scheme and another proposed by Friesen (2003) that is designed to minimize the inspections regulators must make to achieve a target rate of compliance. Both the rules use the current audit record of the firm to assign them to different audit groups in future periods, but in Friesen's scheme all of the transitions between audit groups can be probabilistic, while in Harrington's scheme all transitions are deterministic except for the movement of an inspected, compliant firm from the bad group to the good group. In Friesen's optimal targeting scheme the firms face a fixed probability of moving from the good group to the bad group which is independent of compliance status in the current period. There are no inspections conducted of firms in the first group. Clark et al. find an enforcement possibility frontier between compliance and minimizing inspections, with the Friesen rule requiring slightly lower inspection rates. Their experiment focuses on a comparison of the two conditional audit rules against simple random auditing for a single compliance cost and one set of enforcement parameters in each rule. Harrington's rule performs well on certain measures, such as for the rate of compliance per inspection. This suggests that further exploration of the performance of this enforcement policy is warranted, and in the present study we consider seven different enforcement parameter and compliance cost combinations to more fully examine its empirical properties. These multiple treatments allow us to study how compliance choices respond to different enforcement rules, and estimate a boundedly rational 
choice model to characterize behavioral responses for this type of probabilistic enforcement.

\section{2: Theoretical Framework}

We are interested in the relationship between the firm's compliance cost, its compliance decisions, and the conditional audit scheme chosen by the regulator. Our experiment is structured by Harrington's (1988) model, which determines for a two-state model the level of compliance that can be achieved when both enforcement budgets and the maximum feasible penalty are limited. Let $G_{1}$ and $G_{2}$ denote the two "inspection" groups of firms and denote the inspection probability in $G_{i}$ as $p_{i}$ and the penalty for violation as $F_{i}$, with $p_{1}<p_{2}$ and $F_{1}<F_{2}$. Firms can avoid a violation by incurring the compliance $\operatorname{cost} c$. If a firm is inspected its compliance status is observed perfectly. ${ }^{3}$ Firms found to be in violation in $G_{1}$ are punished by a transfer into $G_{2}$ and firms found to be in compliance in $G_{2}$ are rewarded with a chance of a return to $G_{l}$. The probability that a firm found in compliance in $G_{2}$ is returned to $G_{1}$ is denoted by $u$. Table 1 presents the payoffs to the firm in this game. For future reference, this table also includes the parameters chosen for the experiment.

A policy for the firm is a map $f:\{1,2\} \rightarrow\{0,1\}$ of states 1 and 2 into decisions to comply with (0) or violate (1) the regulations. The firm's goal is to choose the policy that minimizes the present value of its expected costs over an infinite horizon. The firm has four available policies: $f_{00}, f_{01}, f_{10}$ and $f_{11}$, where $f_{00}$ is the policy that the firm would comply in both state 1 and 2 and $f_{01}$ is the policy of complying when in $G_{1}$ and violating when in $G_{2}$ and so on. The expected present value of the policy would be the cost this period plus the expected present value discounted one

\footnotetext{
${ }^{3}$ This is not a critical assumption for Harrington's two-state model, but it is for other models. Greenberg (1984) showed that a three-state model, in which transitions out of a third, "habitual offender" group were impossible, can dramatically reduce the rate of violations compared to a two-state model. But if false positives are possible, where compliant firms are wrongly classified as violators with some positive probability, every firm eventually moves into the third group and all firms are inspected every period.
} 
period. This leads to four sets of simultaneous equations which can be solved to obtain the present values of the four policies. For example, the expected cost of policy $f_{10}$ in state 1 is:

(1) $\frac{c p_{1} \beta+p_{1} F_{1}\left(1-\beta+p_{2} u \beta\right)}{(1-\beta)\left(1-\beta+p_{1} \beta+p_{2} u \beta\right)}$

and the expected cost of $f_{10}$ in state 2 is:

$$
\frac{c\left(1-\left(1-p_{1}\right) \beta\right)+\beta p_{2} u p_{1} F_{1}}{(1-\beta)\left(1-\beta+p_{1} \beta+p_{2} u \beta\right)},
$$

where $\beta$ is the discount factor.

Harrington shows (his Lemma 1 ) that in this framework, $f_{01}$ is never an optimal policy as it is dominated by $f_{00}$ when the cost of compliance $c<p_{2} F_{2}$ and by $f_{11}$ when $c \geq p_{2} F_{2}$. Hence the firm chooses between three policies $f_{00}, f_{10}, f_{11}$ and the optimal policy depends on the compliance costs facing the firm and the enforcement parameters chosen by the regulatory agency. Table 2 presents the expected payoff for each policy, based on an exogenous per-period revenue of $R$. Firms with compliance costs below a particular threshold $\left(p_{1} F_{l}\right)$ always comply, and those with costs above a higher threshold never comply. For an intermediate range of costs the firm chooses policy $f_{10}$, and it cheats when in $G_{1}$ and complies in $G_{2}$. Ironically, for these intermediate compliance costs the "good guys" in $G_{1}$ can afford to cheat, whereas the "bad guys" in $G_{2}$ comply until they are moved back into $G_{1}$. Compared to a static model, in this dynamic model compliance is achieved in $G_{2}$ even though the expected penalty is not large, because firms in $G_{2}$ may be allowed to return to $G_{l}$ depending on their compliance record.

The enforcement agency in this model wants to minimize the resources spent on monitoring and enforcement subject to achieving a target compliance rate $Z$. The agency has five parameters that can be changed to achieve desired compliance rates: the probability of inspections, $p_{1}$ and $p_{2}$, the two penalties $F_{l}$ and $F_{2}$ and the probability $u$ of the firm moving back 
into $G_{l}$ if found compliant. We manipulate $u$ as well as the compliance cost $c$ as exogenous treatment variables in the experiment. For certain parameters-specifically the $u=0.9$, compliance cost $=200$ treatment described below-firms have an incentive to comply even though the expected penalty $\left(p_{2} F_{2}=0.5 \times 300=150\right)$ is less than the single period compliance cost. This property is termed leverage in the literature.

In the optimal combination of enforcement parameters characterized by Harrington, marginal firms that adopt policy $f_{10}$ just slightly prefer to comply rather than violate in $G_{2}$. In our choice of parameters described in the next section, we avoid these optimal parameter cases in which individuals are nearly indifferent between two strategies. This design choice is guided by experience with previous experiments, which demonstrate that more than marginal incentives are necessary for subjects to learn optimal behavior. This is confirmed by the noisy choice model results reported in Section 4.3.

\section{3: Experimental Design}

We conducted 13 sessions with 8 or 9 subjects in each session. All 114 subjects were undergraduate students at Purdue University and were inexperienced in the sense that they had not participated in a similar experiment. The University of Zurich's z-tree program was employed to conduct all sessions (Fischbacher, 1999). Each session lasted about 45 minutes, including instruction time. Payoffs in the experiment were converted using an exchange rate of 1500 experimental dollars $=1$ U.S. dollar and subject earnings ranged from 6.75 to 15.25 U.S. dollars, with median earnings of $\$ 12.75$. These sessions constituted the first half of a longer session that trained subjects to make compliance choices in a study of emissions permit trading with imperfect enforcement (Cason and Gangadharan, 2004). Each subject made 61 separate 
compliance choices over seven different period sequences.

At the start of each period sequence, subjects were initially randomly assigned into inspection group 1 or 2, which differ in the probability of inspections and severity of fine. Each subject had a binary choice: whether to comply or violate in each period. If they decided to comply they paid a compliance cost, which remained unchanged within a period sequence but varied across period sequences. Subjects were inspected with a certain probability that depended on which group they were in. Group 1 subjects were inspected with a probability of 20 percent and group 2 subjects were inspected with a probability of 50 percent. Subjects were required to pay a fine if they did not comply in a particular period and they were inspected. The fine for violation was 50 experimental dollars in group 1 and 300 experimental dollars in group 2. In addition, subjects in group 1 were moved to group 2 when they were caught violating. If subjects were in group 2 and they are observed to comply on inspection, then they were moved back into group 1 with a low or a high probability. The instructions, attached in the appendix, were framed using the terminology of this paragraph (i.e., "comply," "violate," "inspection," "fine," and so on). Comparison of our results with the more neutrally-framed terminology employed in Clark et al. (2004) suggests that framing does not have a substantial impact on the results. ${ }^{4}$

Each subject participated in a random number of periods in seven separate period sequences. The number of periods in each period sequence was determined before the session and was unknown to the subjects. Subjects in the same session faced the different treatments in different orders, which implies that our treatment comparisons control for sequencing effects.

\footnotetext{
${ }^{4}$ For example, Clark et al. (2004) use "Option A" and "Option B" instead of "Comply" and "Violate." Our leverage treatment with compliance cost $=200$ and $u=0.9$ is most similar to the one treatment Clark et al. study, in that violation is optimal in group 1 and compliance is optimal in group 2, even though the compliance cost exceeds the expected fine in group 2. Clark et al. observe overall compliance rates of 12 percent in group 1 and 75 percent in group 2, whereas in our similar treatment we observe overall compliance rates of 11 percent in group 1 and 63 percent in group 2 . While obviously not identical, these rates are similar-especially considering the many other procedural, training and payment design differences between our and Clark et al.'s experiment.
} 
The random ordering also leads to an approximately equal number of decisions in each treatment. As explained in the instructions, each period there was a 90 percent chance that the same period sequence continued for an additional period. This implements a discount factor $\beta=0.9$. Subjects were only told at the end of the last period in a sequence that a new period sequence would now begin.

The period sequences were a combination of two treatment variables, both varied within sessions, in a three-by-two factorial design. For one treatment variable we vary the compliance costs $(c)$ across three levels from low to medium to high to determine whether subjects change their compliance decisions in the presence of different levels of compliance costs. The compliance costs are 100 in the low cost scenario, 200 in the medium cost and 375 in the high cost case. For the other treatment variable we manipulate at two levels the probability $(u)$ of subjects moving from group 2 to group 1 to determine whether subjects comply more when the probability of switching groups is higher. Subjects face a switching probability of 0.1 in some period sequences and 0.9 in others. As noted above, these enforcement parameters do not represent the "optimal" parameters derived in the Harrington model; instead, they reflect our design goal to explore a variety of compliance conditions with strong and weak incentives to comply or violate in the different inspection groups. We also employ a seventh treatment that served as a baseline with very low compliance costs (7) and $u=0.9$, for which compliance is always optimal. All subjects made compliance decisions in all treatment variable combinations.

\section{4: Results}

\section{$\underline{4.1}$ Overall Violation Rates}

Figure 1 presents the average violation rate for later periods in the period sequences, 
along with the steady state predicted violation rates, for each of the seven treatments. The predicted violation rate is 0 when compliance policy $f_{00}$ is optimal, and it is 1 when compliance policy $f_{11}$ is optimal. When policy $f_{10}$ is optimal, the predicted violation rate is the stationary probability of being in inspection group $1, p_{2} u /\left(p_{1}+p_{2} u\right)$. The figure shows that violations usually increase when they are predicted to increase, but that they do not reach the corner solution rates of 0 or 1 when policies $f_{00}$ or $f_{11}$ are optimal.

Table 3 presents the overall violation rates separately for the compliance cost $(c)$, switching probability $(u)$ and inspection group combinations. The model predicts that for our experimental parameters, subjects will violate whenever they are in inspection group 1 except for the baseline treatment with a very low compliance cost of 7 . Table 3 a shows that this prediction is broadly supported, with observed violation rates of subjects in group 1 between 73 and 93 percent when violation is predicted. These rates typically increase for the later sequences 5-7 when subjects have more experience across treatments, as shown in parentheses in the table. The violation rate is 17 percent in the baseline treatment, for which violation is not predicted.

For the parameters employed in the experiment, the model predicts violation in only 3 of the 7 treatment cells when subjects are in inspection group 2. Subjects should not violate in the low compliance cost (7 and 100) case and should violate in the high compliance cost (375) case, irrespective of the value of the switching probability $u$. In the medium compliance cost (200) case they should violate only when they are unlikely to escape from inspection group $2(u=0.1)$. Table $3 \mathrm{~b}$ indicates that violations are more common when they are predicted, but that in all 7 cases the violation rates differ from the predicted rates by at least 13 percentage points, even 
when considering only the late sequences 5-7. Violations also rise when moving to the right or upward in Table $3 b .^{5}$

Table $3 \mathrm{~b}$ clearly shows that subjects do not dramatically switch from never violating to always violating when the expected return from violating exceeds the expected return from compliance. Figure 2 illustrates the contrast between the sharp never/always violate prediction of the model and the smoothly monotonically increasing violation rate observed in the experiment. This figure is based on choices in inspection group 2 only, and it also displays the ratio of expected profits from violating to the expected profits from compliance. These expected profits are based on the discounted, infinitely repeated compliance choice problem with the optimal compliance policy followed in all subsequent periods. The model predicts a violation rate of 1 if and only if this ratio exceeds 1 . The observed violation rate, however, is merely higher whenever this ratio indicates a higher return to violation. (An exception to this occurs for one transition: compliance $\operatorname{cost}=200$ and $u=0.1$ to compliance $\operatorname{cost}=375$ and $u=0.9$.) In other words, subjects' choices appear to be sensitive to the relative payoffs from violation and compliance, but the overall averages do not switch from one corner solution prediction to the other at the sharp threshold when the ratio passes through one. We return to this issue in Section 4.3 where we explain this behavior using a simple model of boundedly-rational, or "noisy," decision-making.

Clearly the data do not support the point predictions of the model, but they are consistent with many of the comparative static predictions about how the compliance rates differ in the various treatment cells. For formal tests we do not use the overall averages displayed in Table 3,

\footnotetext{
5 These deviations from the optimal compliance choices are not explained by individual subjects who were "chronic" violators or by subjects who may derive utility from being "honest" and comply constantly even when violation is more profitable. Indeed, we find no evidence that such extreme behaviors were present, based on our analysis of individual subjects' play. All subjects violated at least one-third of the time and complied at least 15 percent of the time. As shown below, most individual subjects' compliance choices changed in response to the different incentives generated by the different enforcement treatments.
} 
since individual subjects made multiple compliance choices and therefore the data points in this table are not statistically independent. Fortunately, we can conduct rather powerful tests based on statistically independent observations of individual subjects' compliance rates and compliance rate differences across treatment cells. Recall that 114 individual subjects participated in this study, and they did not interact at all so each provides statistically independent observations. Therefore, for example, to test whether the violation rate in inspection group 2 for $u=0.9$ is significantly higher when compliance cost $=375$ than when compliance cost $=200$, we first calculate the violation rate for each individual subject within those two treatment cells. We then calculate the difference in these rates for the 70 individual subjects who made choices in both treatment cells, and employ a nonparametric Wilcoxon Signed Rank test to determine whether these differences are significantly different from zero.

This statistically conservative and yet powerful (due to our sample size) procedure yields the following conclusions. All statements are based on a five-percent significance threshold.

First, violation rates are significantly higher when in inspection group 1 than when in inspection group 2 for all 7 treatment cells. Note that the model predicts a significant difference in only 3 of the treatment cells (i.e., for both $u=0.1$ and 0.9 when compliance cost $=100$ and when $u=0.9$ and compliance cost $=200$ ).

Second, when in inspection group 1 the violation rate increases significantly when the compliance cost increases in 3 of the 5 pairwise comparisons: for $u=0.1$ when moving from compliance cost $=100$ to 200 , and for $u=0.9$ when moving from compliance cost $=7$ to 100 and when moving from 100 to 200 . When in inspection group 2 the violation rate increases significantly when the compliance cost increases in 4 of the 5 pairwise comparisons: all cases except for $u=0.9$ when moving from compliance cost $=7$ to 100 . Note that the data support all 3 
compliance cost treatment effects predicted by the model (for $u=0.1$, when moving from compliance cost $=100$ to 200 in inspection group 1 , and for $u=0.9$, when moving from compliance cost=200 to 375 in inspection group 2 and when moving from compliance cost $=7$ to 100 in inspection group 1). However, also note that 4 additional differences are also significant (these are, for $u=0.1$, when moving from compliance cost=100 to 200 in inspection group 1 and from compliance $\operatorname{cost}=200$ to 375 in inspection group 2 ; and for $u=0.9$, when moving from compliance cost $=100$ to 200 in both inspection groups)..

Third, the violation rate is significantly higher when $u=0.1$ than when $u=0.9$ for all 3 pairwise comparisons when subjects are in inspection group 2. This is predicted only for the medium compliance cost=200 case, where the leverage of the two inspection groups is greatest. The violation rate is not significantly different for any of the 3 pairwise $u$ comparisons when subjects are in inspection group 1 , as predicted by the model.

These statistical conclusions generally hold for alternative subsets of the data, including for compliance choices based on only the initial inspection group that subjects are randomly assigned to, or compliance rates based only on subjects who have at least three compliance choices for a particular treatment cell. They are also robust to alternative statistical tests such as a simple nonparametric sign test or the standard parametric $t$-test.

\subsection{Classification of Strategies}

The violation rates just analyzed separately for each compliance cost $(c)$, switching probability $(u)$ and inspection group combination employ a state-by-state perspective of this choice problem that differs from the strategy specification of Harrington's model. Recall that agents in the model adopt an entire compliance policy; for example, if they adopt strategy $f_{10}$ they violate when in inspection group 1 and comply when in inspection group 2. Therefore, in 
this section we examine the entire sequence of compliance choices within treatment cells to classify individual subjects' compliance policies. The main difficulty we encounter in this classification is that some subjects do not make choices in both inspection groups and so their observed choices are consistent with multiple policies. Table 4 presents the classification for only those subjects who can be perfectly classified into a specific strategy for a particular treatment, and Table 5 classifies every subject based on her "best-fitting" strategy.

Table 4 classifies an individual subject as choosing compliance policy $f_{11}$ for a particular treatment cell if they always violate in that cell, regardless of which inspection group they are in. We classify an individual in compliance policy $f_{10}$ for a cell if they always violate when in inspection group 1 and never violate when in inspection group 2. The classifications for $f_{01}$ and $f_{00}$ are defined analogously. Some subjects never make choices in one of the inspection groups for some treatment cells, so we have no data to classify their behavior in that group. These cases are denoted with question marks. For example, $f_{1 \text { ? }}$ indicates that a subject always violated in inspection group 1, but never made decisions in inspection group 2. This individual's behavior is consistent with both $f_{10}$ and $f_{11}$. In the summary sections in Table 4 we count observations as consistent with $f_{10}$, for example, if they are identified in the "frequency (rate)" section as $f_{1 ?}, f_{? 0}$ or $f_{10}$. Likewise, we count observations as consistent with $f_{11}$ if they are identified in the "frequency (rate)" section as $f_{1 ?}, f_{? 1}$ or $f_{11}$, and we count observations as consistent with $f_{00}$ if they are identified in the "frequency (rate)" section as $f_{0 ?}, f_{? 0}$ or $f_{00}$. The percentage of individuals who are classifiable as consistent with each policy does not sum to 100 percent because of the "question mark" subjects whose choices are consistent with two policies.

Clearly we have a large number of subjects who are not classifiable into any policy, ranging from 37 to 70 percent of the individuals depending on the treatment cell. In Table 5 we 
therefore present an alternative classification based on the policy that provides a best-fit to each individual subject's choices. This simple procedure counts the number of "errors" assuming subjects follow a particular strategy, and yields a strategy classification for every subject that minimizes the number of errors in classification. For some subjects, however, two policies are equally best-fitting. This occurs most frequently when subjects do not make choices in both inspection groups.

The results are largely consistent across the two classification methods in the two tables. Both indicate that more subjects are consistent with the optimal policy (shown in bold on the tables) than any other policy for 6 treatment cells, with the exception being the cell where compliance cost is medium and $u=0.1$. In this cell, for example, Table 5 shows that 60 percent are consistent with policy $f_{10}$ and 54 percent are consistent with the optimal policy $f_{11}$. For all other conditions, at least two-thirds of the subjects' strategies are consistent with the optimal policy. The switching probability $u$ can be an important determinant in the individual's decision making, particularly so when the compliance costs are high. When the compliance costs $=375$, more subjects are consistent with $f_{10}$ when $u=0.9$ than when $u=0.1$, although the optimal policy $f_{11}$ is still played by a larger percentage of the subjects. For these high compliance costs-which are more than double the single period expected penalty—apparently some individuals increase their compliance rates because of the greater opportunity of moving back to the good group 1 as $u$ increases. This suggests that leverage works to some degree even when it is not predicted to work by the model.

Taken together, these points concerning the classification rates suggest that (1) some subjects' behavior is either confused or consistent with some alternative model we have yet to consider; and (2) a large portion of subjects choose the compliance policy predicted by the 
Harrington model. The next subsection presents an alternative choice model in an attempt to make sense of some of the systematic deviations from this model.

\subsection{A Noisy Choice Model}

The Harrington model predicts that subjects choose the optimal compliance policy with probability one, regardless of whether this policy provides a return that is, for example, 331 percent higher or 10 percent higher than the next best alternative. Figure 2, however, shows that although subjects are more likely to choose strategies that provide greater expected profits, their likelihood of choosing the optimal strategy increases when its return is greater relative to its alternatives. This suggests that a "noisy choice" model that permits errors in decision-making might be useful to understand our experimental outcomes. In what follows we employ a "quantal choice" model that accounts for boundedly-rational decision-making. This model allows subjects to make errors, but it accounts, in an intuitive way, for the fact that subjects are less likely to make errors that are more costly. ${ }^{6}$

We use the logit form of the quantal choice model first introduced by Luce (1959) and popularized more recently by McKelvey and Palfrey (1995) in a game-theoretic context as a quantal response equilibrium. In our study subjects are not playing a strategic game—-just a game against nature since the inspector is not strategic. The idea is therefore quite simple: If strategy $i$ has utility $U_{i}$, it is played with probability

(3) $q_{i}=\frac{\exp \left(U_{i} / \mu\right)}{\sum_{\text {all } j} \exp \left(U_{j} / \mu\right)}$

The parameter $\mu$ is estimated from the data and scales the sensitivity that subjects have to the

\footnotetext{
${ }^{6}$ Figure 2 clearly shows how deviations from the optimal choice depend on the relative profitability of the different choices, and thus rejects alternative choice error models like the Noisy Nash model that do not account for relative payoffs. In the Noisy Nash model the agent makes his optimal choice with probability $\gamma$ and randomizes (uniformly) over all choices, independent of their relative payoffs, with probability $1-\gamma$ (McKelvey and Palfrey, 1998).
} 
relative payoffs (in terms of utility) of the various choices. As $\mu$ decreases the subjects put less probability weight on choices that yield suboptimal choices, and the probability that they make the optimal choice approaches one as $\mu$ approaches zero. As $\mu$ approaches infinity, subjects choose their available strategies with equal probability, independent of the relative expected payoffs.

This framework also allows us to determine if risk aversion, either as a competing or a complementary explanation to this type of boundedly rational decision making, might also explain the deviations from optimal choices. Risk aversion is sometimes argued to lead to higher compliance rates than is predicted as risk averse subjects could be very sensitive to the probability of being caught (Alm, Jackson and McKee, 1992). The greater risk of a fine increases the cost of violating while leaving unchanged the returns from complying. To introduce risk aversion in a simple way we posit a constant relative risk averse utility function for each subject of the form $U(\pi)=\pi^{1-\alpha} /(1-\alpha)$, where $\pi$ is the dollar payoff for the choice and $\alpha$ is the index of relative risk aversion. We can estimate both $\mu$ and $\alpha$ by maximum likelihood techniques within the same model. If $\alpha$ is significantly positive while $\mu$ is near zero, this would suggest that risk aversion rather than bounded rationality is a primary cause of the deviations from the optimal choice. We obtain the opposite result, however. In all of our estimates, whether looking at only late periods, only early periods, or all decisions, we find the maximum likelihood estimate of $\alpha$ to be 0 but $\mu$ to be positive and highly significant. Therefore, we reject risk aversion as a main explanation of our results and focus on the bounded rationality term $\mu$.

To evaluate this model we look at individual choices within an inspection group, similar to the analysis in Section 4.1 above (and Table 3). We consider 3 choices for the subjects: compliance policies $f_{00}, f_{10}$ and $f_{11}$, but not policy $f_{01}$ since $f_{01}$ is never optimal and is always 
played less frequently than other policies (as documented in Tables 4 and 5). We translate the rates at which subjects choose these compliance strategies into observed violation rates for each inspection group. Table 6 presents the maximum likelihood estimate for $\mu$, pooling across all 6 main treatment cells (i.e., all treatments except the baseline compliance cost=7). We present results for all periods pooled, as well as results separating the early session treatment sequences from the late session treatment sequences. Consistent with previous research that employs this quantal choice approach (e.g., McKelvey and Palfrey, 1995), the choice errors decline as subjects gain experience. This is reflected in the significantly lower $\mu$ estimate for the late period sequences.

Figure 3 illustrates the remarkable success that this simple, one-parameter model has in explaining the deviations from the optimal choices, based on the pooled estimate for the entire dataset. $^{7}$ It is important to keep in mind that the noise parameter does not provide freedom to explain any deviations; instead, each particular value of $\mu$ is consistent with only one specific combination of deviations across our treatments. Nevertheless, all of the observed violation rates are accurately predicted by the model, with the greatest deviation only 14 percent. Moreover, the model accurately captures the qualitative differences across treatments, such as the higher group 1 violation rates when the compliance cost is greater.

\section{5: Discussion}

Enforcement and monitoring of regulatory compliance policies can incur substantial resource costs. Dynamic audit models help us in understanding how individuals and firms might behave when faced with enforcement and compliance rules that are conditional on actions in

\footnotetext{
${ }^{7}$ We could obviously fit the observed rates more accurately with treatment cell-specific $\mu$ estimates. As Haile et al. (2003) have recently emphasized, however, it is important to leave the estimated parameter unchanged across treatments to make comparative statics exercises informative.
} 
previous and current periods. Harrington's (1988) important model demonstrates how a regulator could use multiple inspection groups to increase enforcement leverage when political or other practical considerations limit the size of fines. While there is a body of theoretical research in this area, empirical analysis of the compliance strategies of individuals in this dynamic framework is limited by a lack of observability for key variables in the theories.

Laboratory evidence presented in this paper shows that in a broad sense many subjects' behavior is consistent with the theoretical predictions of this dynamic enforcement model. Overall violation rates are significantly higher in group 1 than in group 2 . When compliance costs are higher then the violation rates increase significantly. We also obtain clear support for the more subtle prediction that compliance increases in the "bad" group 2 if it is more likely to be rewarded with a transition back to the "good" group 1. That is, our results support the general idea of enforcement leverage through transitions across multiple groups.

An examination of the compliance policies chosen by the subjects reveals that a large proportion of the subjects choose the strategy predicted by the Harrington model. Subjects in our experiments do not, however, follow the sharp predictions of the model. The deviations are more pronounced when the model makes corner solution predictions even though the differences in expected profits are marginal for alternative policies or actions. To account for this we consider a quantal choice model where subjects are assumed to be boundedly rational. When faced with regulatory policies, the standard rational choice model assumes that firms and individuals would choose strategies that increase their payoffs. They might not choose the exact optimal strategy at all times; i.e., they may make some mistakes, although it seems sensible that they would tend to make fewer mistakes when the mistakes are more costly. This aspect of bounded rationality is often neglected in a policy setting. 
To understand firm behavior and formulate policies that provide incentives for better regulatory enforcement, our results suggest that more attention can be paid to models that incorporate noisy decision making. The quantal choice model accurately accounts for the boundedly rational behavior of our laboratory subjects, and it may also be useful for describing compliance choices of agents in the field. Enforcement models themselves might also be more accurate if they incorporate bounded rationality explicitly. For example, the Harrington model implies optimal endogenous enforcement parameters to maximize efficiency (for each particular compliance cost) in which the firm only slightly prefers to comply rather than violate in the high intensity inspection group. Since at this margin the firm is nearly indifferent between the two strategies, the alternative behavioral prediction from the quantal choice model instead predicts that the firm would comply only about half the time. 


\section{References}

Alm, J. and M. McKee (1998) Extending the Lessons of Laboratory Experiments on Tax Compliance to Managerial and Decision Economics. Managerial and Decision Economics, 19, Pages 259-275.

Alm, J., M. Cronshaw and M. McKee (1993) Tax Compliance with Endogenous Audit Selection Rules. Kyklos, 46, Pages 27-45.

Alm, J., Jackson, B and M. McKee (1992) Institutional Uncertainty and Taxpayer Compliance. American Economic Review, 82(4), Pages 1018-1026.

Arora, S. and S. Gangopadhyay (1995), Toward a Theoretical Model of Voluntary Overcompliance, Journal of Economic Behavior and Organization, 28, Pages 289-309.

Cason, T. and L. Gangadharan (2004) Emissions Variability in Tradable Permit Markets with Imperfect Enforcement and Banking. Mimeo, Purdue University.

Clark, J., L. Friesen and A. Muller (2004) The Good, the Bad and the Regulator: an Experimental Test of Two Conditional Audit Schemes. Economic Inquiry, 42, Pages 69-87.

Eckert, H. (2004) Inspections, Warnings and Compliance: The Case of Petroleum Storage Regulation, Journal of Environmental Economics and Management, 47, Pages 232-259.

Fischbacher, U. (1999) z-Tree - Zurich Toolbox for Readymade Economic Experiments, Working Paper No. 21, Institute for Empirical Research in Economics, University of Zurich.

Friesen, L (2003) Targeting Enforcement to improve Compliance with Environmental Regulations. Journal of Environmental Economics and Management, 46(1), Pages 72-86.

Greenberg, J (1984) Avoiding Tax Avoidance: A (Repeated) Game-theoretic Approach. Journal of Economic Theory, 32(1), Pages 1-13.

Haile, P., A. Hortaçsu, and G. Kosenok (2003) On the Empirical Content of Quantal Response Equilibrium, Cowles Foundation Discussion Paper No. 1432, Yale University.

Harford, J (1978) Firm Behavior under Imperfectly Enforceable Standards and Taxes, Journal of Environmental Economics and Management, 5(1), Pages 26-43.

Harrington, W (1988) Enforcement Leverage When Penalties are Restricted. Journal of Public Economics 37, Pages 29-53.

Helland, E (1998) The Enforcement of Pollution Control Laws: Inspections, Violations and Self Reporting. Review of Economics and Statistics, 80 (1), Pages 141-153.

Landsberger, M and I. Meilijson (1982) Incentive Generating State Dependent Penalty System: The case of Income Tax Evasion. Journal of Public Economics, 19, Pages 333-352. 
Linder, S and M. McBride (1984) Enforcement Costs and Regulatory Reform: The Agency and Firm Response. Journal of Environmental Economics and Management, 11, Pages 327-346.

Luce, R. D., Individual Choice Behavior: A Theoretical Analysis. New York: John Wiley and Sons, 1959.

McKelvey, R., and T. Palfrey, T. (1995) Quantal Response Equilibria in Normal Form Games. Games and Economic Behavior 7, Pages 6-38.

McKelvey, R., and Palfrey, T. (1998) Quantal Response Equilibria for Extensive Form Games. Experimental Economics 1, Pages 9-42.

Oljaca, N., A. G. Keeler and J. Dorfman (1998) Penalty Functions for Environmental Violations: Evidence from Water Quality Enforcement. Journal of Regulatory Economics, 14, Pages 255264.

Salop, S. and D. Scheffman (1983), Raising Rivals' Costs, American Economic Review (Paper and Proceedings) 73(2), Pages 267-271.

Storey, D. and P. McCabe (1980) The Criminal Waste Discharger. Scottish Journal of Political Economy, 27(1), Pages 30-40.

Torgler, B. (2002) Speaking to Theorists and Searching for Facts: Tax Morale and Tax Compliance in Experiments. Journal of Economic Surveys, 16 (5), Pages 657-683. 
Table 1: Payoff Parameters for Enforcement Game

\begin{tabular}{|l|l|l|l|l|l|}
\hline & \multicolumn{2}{|c|}{ Group 1 } & \multicolumn{2}{c|}{ Group 2 } \\
\hline & Comply & \multicolumn{2}{|c|}{ Violate } & Comply & \multicolumn{2}{c|}{$p_{2}=0.5$} \\
\hline $\begin{array}{l}\text { Inspection } \\
\text { Probability }\end{array}$ & \multicolumn{2}{|c|}{$p_{1}=0.2$} & \multicolumn{2}{c|}{} \\
\hline No Inspection & $\begin{array}{l}c=100,200,375 \\
\text { (baseline } c=7)\end{array}$ & 0 & $\begin{array}{l}c=100,200,375 \\
\text { (baseline } c=7)\end{array}$ & 0 \\
\hline & & & & \\
\hline Inspection & $c=100,200,375$ & $F_{1}=50$ & $c=100,200,375$ & $F_{2}=300$ \\
\hline & & $\begin{array}{l}\text { moved to } G_{2} \\
\text { with Prob }=1\end{array}$ & $\begin{array}{l}\text { Prob }(\text { moved } \\
\left.\text { back to } G_{1}\right)=u \\
=0.1,0.9\end{array}$ & \\
\hline
\end{tabular}

Table 2: Expected Payoff of Alternative Policies

\begin{tabular}{|l|c|c|}
\hline Policy & Expected Payoff if in Group 1 & Expected Payoff in Group 2 \\
\hline $\begin{array}{l}\text { Always comply: } \\
f_{00}\end{array}$ & $\frac{R-c}{1-\beta}$ & $\frac{R-c}{1-\beta}$ \\
\hline $\begin{array}{l}\text { Comply only in } \\
\text { Group 1: } f_{10}\end{array}$ & $\frac{R}{1-\beta}-\frac{c p_{1} \beta+p_{1} F_{1}\left(1-\beta+p_{2} u \beta\right)}{(1-\beta)\left(1-\beta+p_{1} \beta+p_{2} u \beta\right)}$ & $\frac{R}{1-\beta}-\frac{c\left(1-\left(1-p_{1}\right) \beta\right)+\beta p_{2} u p_{1} F_{1}}{(1-\beta)\left(1-\beta+p_{1} \beta+p_{2} u \beta\right)}$ \\
\hline $\begin{array}{l}\text { Never comply: } \\
f_{11}\end{array}$ & $\frac{R}{1-\beta}-\frac{p_{1} F_{1}(1-\beta)+\beta p_{1} p_{2} F_{2}}{(1-\beta)\left(1-\left(1-p_{1}\right) \beta\right)}$ & $\frac{R-p_{2} F_{2}}{1-\beta}$ \\
\hline
\end{tabular}


Table 3a: Predicted and Observed Violation Rates for Inspection Group 1

\begin{tabular}{|c|c|c|c|c|c|}
\hline $\begin{array}{c}\text { Probability an } \\
\text { Inspected, Compliant } \\
\text { Firm Exits Group } 2 \\
\end{array}$ & & $\begin{array}{c}\text { Compliance } \\
\text { Cost }=7\end{array}$ & $\begin{array}{c}\text { Compliance } \\
\text { Cost }=100\end{array}$ & $\begin{array}{c}\text { Compliance } \\
\text { Cost }=200\end{array}$ & $\begin{array}{c}\text { Compliance } \\
\text { Cost }=375\end{array}$ \\
\hline \multirow[t]{2}{*}{$u=0.1$} & $\begin{array}{l}\text { Observed } \\
\text { Violation Rate }\end{array}$ & & $\begin{array}{l}371 / 511=73 \% \\
(158 / 206=77 \%)\end{array}$ & $\begin{array}{c}210 / 243=86 \% \\
(59 / 68=87 \%)\end{array}$ & $\begin{array}{c}198 / 221=90 \% \\
(47 / 50=94 \%)\end{array}$ \\
\hline & $\begin{array}{l}\text { Predicted } \\
\text { Violation Rate }\end{array}$ & & 1 & 1 & 1 \\
\hline \multirow[t]{2}{*}{$u=0.9$} & $\begin{array}{l}\text { Observed } \\
\text { Violation Rate }\end{array}$ & $\begin{array}{c}136 / 795=17 \% \\
(69 / 395=17 \%)\end{array}$ & $\begin{array}{c}506 / 607=83 \% \\
(151 / 177=85 \%)\end{array}$ & $\begin{array}{l}538 / 603=89 \% \\
(210 / 218=96 \%)\end{array}$ & $\begin{array}{l}502 / 539=93 \% \\
(277 / 276=97 \%)\end{array}$ \\
\hline & $\begin{array}{l}\text { Predicted } \\
\text { Violation Rate }\end{array}$ & 0 & 1 & 1 & 1 \\
\hline
\end{tabular}

Note: Data for late sequences 5-7 only are shown in parentheses.

Table 3b: Predicted and Observed Violation Rates for Inspection Group 2

\begin{tabular}{|c|c|c|c|c|c|}
\hline $\begin{array}{c}\text { Probability an } \\
\text { Inspected, Compliant } \\
\text { Firm Exits Group } 2\end{array}$ & & $\begin{array}{c}\text { Compliance } \\
\text { Cost }=7\end{array}$ & $\begin{array}{c}\text { Compliance } \\
\text { Cost }=100\end{array}$ & $\begin{array}{c}\text { Compliance } \\
\text { Cost }=200\end{array}$ & $\begin{array}{c}\text { Compliance } \\
\text { Cost }=375\end{array}$ \\
\hline \multirow[t]{2}{*}{$u=0.1$} & $\begin{array}{l}\text { Observed } \\
\text { Violation Rate }\end{array}$ & & $\begin{array}{l}116 / 526=22 \% \\
(54 / 217=25 \%)\end{array}$ & $\begin{array}{l}359 / 732=49 \% \\
(115 / 244=47 \%)\end{array}$ & $\begin{array}{l}529 / 655=81 \% \\
(229 / 262=87 \%)\end{array}$ \\
\hline & $\begin{array}{l}\text { Predicted } \\
\text { Violation Rate }\end{array}$ & & 0 & 1 & 1 \\
\hline \multirow[t]{2}{*}{$u=0.9$} & $\begin{array}{l}\text { Observed } \\
\text { Violation Rate }\end{array}$ & $\begin{array}{l}28 / 188=15 \% \\
(21 / 130=16 \%)\end{array}$ & $\begin{array}{l}65 / 359=18 \% \\
(20 / 135=15 \%)\end{array}$ & $\begin{array}{c}138 / 369=37 \% \\
(45 / 154=29 \%)\end{array}$ & $\begin{array}{l}255 / 399=64 \% \\
(128 / 204=63 \%)\end{array}$ \\
\hline & $\begin{array}{l}\text { Predicted } \\
\text { Violation Rate }\end{array}$ & 0 & 0 & 0 & 1 \\
\hline
\end{tabular}

Note: Data for late sequences 5-7 only are shown in parentheses. 
Table 4: Compliance Strategy Classification Rates, Allowing for 0\% Error Classification Threshold

\begin{tabular}{|c|c|c|c|c|c|}
\hline $\begin{array}{l}\text { Probability an } \\
\text { Inspected, } \\
\text { Compliant Firm } \\
\text { Exits Group } 2 \\
\end{array}$ & Compliance Policy & $\begin{array}{c}\text { Compliance } \\
\text { Cost }=7\end{array}$ & $\begin{array}{c}\text { Compliance } \\
\text { Cost }=100\end{array}$ & $\begin{array}{c}\text { Compliance } \\
\text { Cost }=200\end{array}$ & $\begin{array}{c}\text { Compliance } \\
\text { Cost }=375\end{array}$ \\
\hline \multirow{10}{*}{$u=0.1$} & $f_{00}$ frequency (rate) & & $0(0 \%)$ & $0(0 \%)$ & $0(0 \%)$ \\
\hline & $f_{01}$ frequency (rate) & & $0(0 \%)$ & $0(0 \%)$ & $0(0 \%)$ \\
\hline & $f_{0 ?}$ frequency (rate) & & $4(4 \%)$ & $0(0 \%)$ & $0(0 \%)$ \\
\hline & $f_{1 ?}$ frequency (rate) & & $6(5 \%)$ & $7(6 \%)$ & $11(10 \%)$ \\
\hline & $f_{10}$ frequency (rate) & & $21(19 \%)$ & $9(8 \%)$ & $2(2 \%)$ \\
\hline & $f_{11}$ frequency (rate) & & $2(2 \%)$ & $3(3 \%)$ & $14(13 \%)$ \\
\hline & $f_{? 0}$ frequency (rate) & & $5(5 \%)$ & $8(7 \%)$ & $0(0 \%)$ \\
\hline & $f_{? 1}$ frequency (rate) & & $2(2 \%)$ & $6(5 \%)$ & $30(28 \%)$ \\
\hline & other freq. (rate) & & $71(64 \%)$ & $77(70 \%)$ & $52(48 \%)$ \\
\hline & Total subjects & & 111 & 110 & 109 \\
\hline \multirow{6}{*}{$\begin{array}{c}u=0.1 \\
\text { Summary }\end{array}$} & $f_{00}$ consistent (rate) & & $9(23 \%)$ & $8(24 \%)$ & $0(0 \%)$ \\
\hline & $f_{10}$ consistent (rate) & & $32(80 \%)$ & $24(73 \%)$ & $13(23 \%)$ \\
\hline & $f_{01}$ consistent (rate) & & $6(15 \%)$ & $6(18 \%)$ & $30(53 \%)$ \\
\hline & $f_{11}$ consistent (rate) & & $10(25 \%)$ & $16(48 \%)$ & 55 (96\%) \\
\hline & Classifiable subjects & & 40 & 33 & 57 \\
\hline & Optimal Policy & & $f_{10}$ & $f_{11}$ & $f_{11}$ \\
\hline \multirow{10}{*}{$u=0.9$} & $f_{f_{00}}$ frequency (rate) & $30(27 \%)$ & $2(2 \%)$ & $0(0 \%)$ & $0(0 \%)$ \\
\hline & $f_{01}$ frequency (rate) & $0(0 \%)$ & $0(0 \%)$ & $0(0 \%)$ & $0(\%)$ \\
\hline & $f_{0 ?}$ frequency (rate) & $31(28 \%)$ & $1(1 \%)$ & $0(0 \%)$ & $0(\%)$ \\
\hline & $f_{1 ?}$ frequency (rate) & $1(1 \%)$ & $3(3 \%)$ & $14(13 \%)$ & $13(12 \%)$ \\
\hline & $f_{10}$ frequency (rate) & $5(5 \%)$ & $45(41 \%)$ & $35(32 \%)$ & $18(16 \%)$ \\
\hline & $f_{11}$ frequency (rate) & $2(2 \%)$ & $0(0 \%)$ & $2(2 \%)$ & $19(17 \%)$ \\
\hline & $f_{? 0}$ frequency (rate) & $1(1 \%)$ & $1(1 \%)$ & $0(0 \%)$ & $0(0 \%)$ \\
\hline & $f_{? 1}$ frequency (rate) & $0(0 \%)$ & $0(0 \%)$ & $1(0.9 \%)$ & $5(5 \%)$ \\
\hline & other freq. (rate) & $41(37 \%)$ & $57(52 \%)$ & $58(53 \%)$ & $56(50 \%)$ \\
\hline & $\overline{\text { Total subjects }}$ & 111 & 109 & 110 & 111 \\
\hline \multirow{6}{*}{$\begin{array}{c}u=0.9 \\
\text { Summary }\end{array}$} & $f_{00}$ consistent (rate) & $62(89 \%)$ & $4(8 \%)$ & $0(0 \%)$ & $0(0 \%)$ \\
\hline & $f_{10}$ consistent (rate) & $7(10 \%)$ & $49(94 \%)$ & $49(94 \%)$ & $31(56 \%)$ \\
\hline & $f_{01}$ consistent (rate) & $31(44 \%)$ & $1(2 \%)$ & $1(2 \%)$ & $5(9 \%)$ \\
\hline & $f_{11}$ consistent (rate) & $3(4 \%)$ & $3(6 \%)$ & $17(33 \%)$ & $37(67 \%)$ \\
\hline & Classifiable subjects & 70 & 52 & 52 & 55 \\
\hline & Optimal Policy & $f_{00}$ & $f_{10}$ & $f_{10}$ & $f_{11}$ \\
\hline
\end{tabular}

Note: The percentage rates shown in the frequency section of the table are percentages of the total number of subjects making choices in that treatment condition. The percentage rates shown in the consistent section of the table are percentages of the classifiable subjects in that treatment condition. These latter percentages sum to greater than 100 percent because some subjects' observed choices are consistent with multiple compliance policies. 
Table 5: Best-Fitting Compliance Strategy for Each Subject in Each Treatment

\begin{tabular}{|c|c|c|c|c|c|}
\hline $\begin{array}{l}\text { Probability an } \\
\text { Inspected, } \\
\text { Compliant Firm } \\
\text { Exits Group } 2 \\
\end{array}$ & Compliance Policy & $\begin{array}{c}\text { Compliance } \\
\text { Cost }=7\end{array}$ & $\begin{array}{c}\text { Compliance } \\
\text { Cost }=100\end{array}$ & $\begin{array}{c}\text { Compliance } \\
\text { Cost }=200\end{array}$ & $\begin{array}{c}\text { Compliance } \\
\text { Cost }=375\end{array}$ \\
\hline \multirow{6}{*}{$u=0.1$} & $f_{00}$ frequency (rate) & & $30(27 \%)$ & $31(28 \%)$ & $8(7 \%)$ \\
\hline & $f_{10}$ frequency (rate) & & $85(77 \%)$ & $66(60 \%)$ & $32(29 \%)$ \\
\hline & $f_{01}$ frequency (rate) & & $20(18 \%)$ & $36(33 \%)$ & $55(50 \%)$ \\
\hline & $f_{11}$ frequency (rate) & & $35(32 \%)$ & $59(54 \%)$ & $96(88 \%)$ \\
\hline & Total subjects & & 111 & 110 & 109 \\
\hline & Optimal Policy & & $f_{10}$ & $f_{11}$ & $f_{11}$ \\
\hline \multirow{6}{*}{$u=0.9$} & $f_{00}$ frequency (rate) & $89(80 \%)$ & $14(13 \%)$ & $3(3 \%)$ & $2(2 \%)$ \\
\hline & $f_{10}$ frequency (rate) & $21(19 \%)$ & $93(85 \%)$ & $88(80 \%)$ & $67(60 \%)$ \\
\hline & $f_{01}$ frequency (rate) & $43(39 \%)$ & $9(8 \%)$ & $9(8 \%)$ & $10(9 \%)$ \\
\hline & $f_{11}$ frequency (rate) & $8(7 \%)$ & $21(19 \%)$ & $49(45 \%)$ & $75(68 \%)$ \\
\hline & Total subjects & 111 & 109 & 110 & 111 \\
\hline & Optimal Policy & $f_{00}$ & $f_{10}$ & $f_{10}$ & $f_{11}$ \\
\hline
\end{tabular}

Note: The percentage rates shown in the frequency section of the table are percentages of the total number of subjects whose choices minimize the number of deviations from the indicated strategy in that treatment condition. The percentages sum to greater than 100 percent because some subjects' observed choices are best fit by two different compliance policies, particularly when they do not make compliance choices in one of the inspection groups.

Table 6: $\quad$ Quantal Choice Model Maximum Likelihood Estimates

\begin{tabular}{cccc}
\hline Dataset & $\begin{array}{c}\mu \text { estimate } \\
\text { (standard error) }\end{array}$ & Log-likelihood & $\begin{array}{c}\text { Number of } \\
\text { Observations }\end{array}$ \\
\hline All Periods & $\begin{array}{c}976 \\
(35)\end{array}$ & -2927.6 & 5764 \\
Early Sequences 1-4 & $\begin{array}{c}1144 \\
(57)\end{array}$ & -1915.4 & 3553 \\
Late Sequences 5-7 & 747 & -992.6 & 2211 \\
\hline \hline
\end{tabular}


Figure 1: Predicted and Observed Overall Violation Rates, by Treatment, for Two Sets of Later Periods

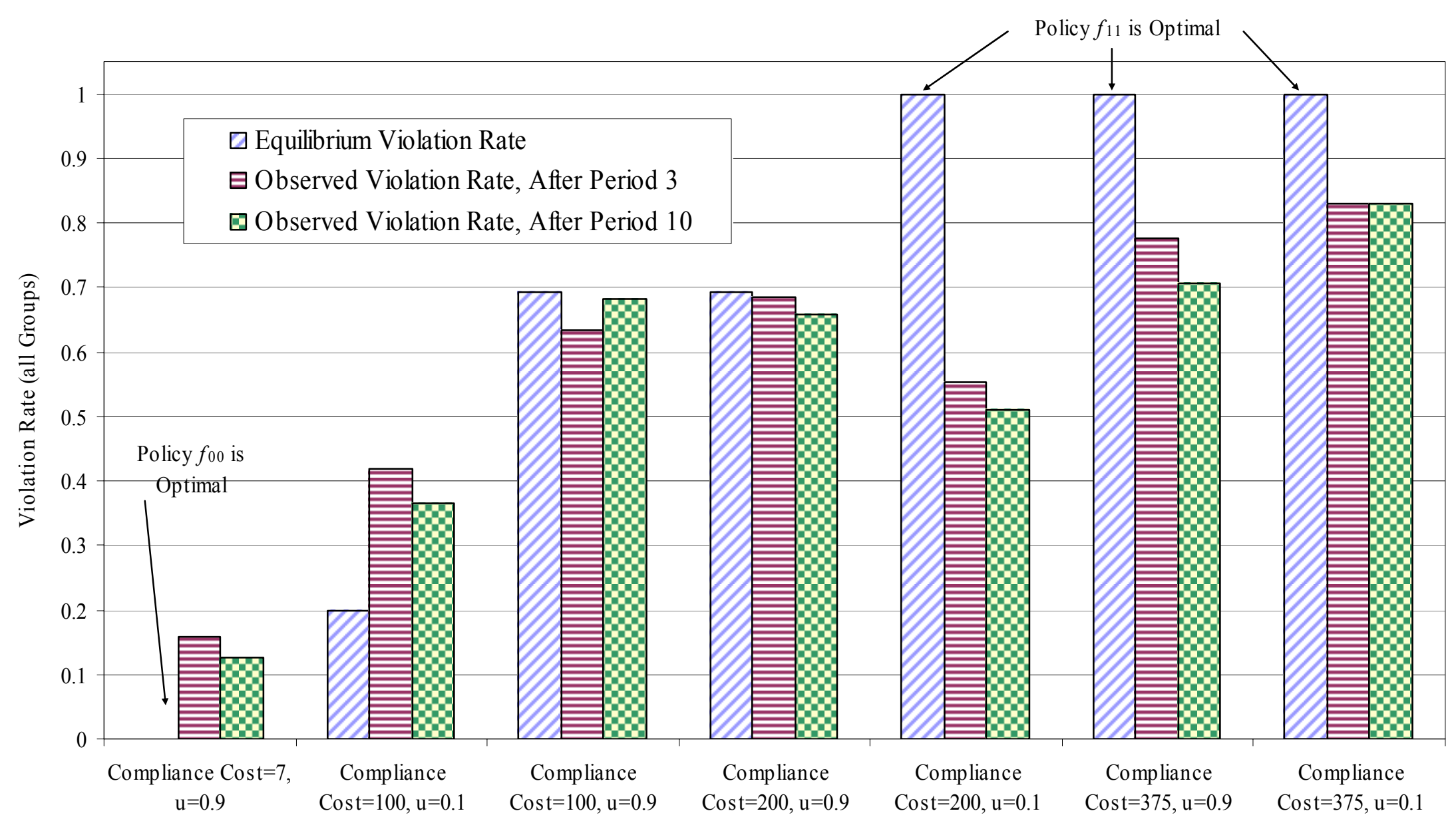




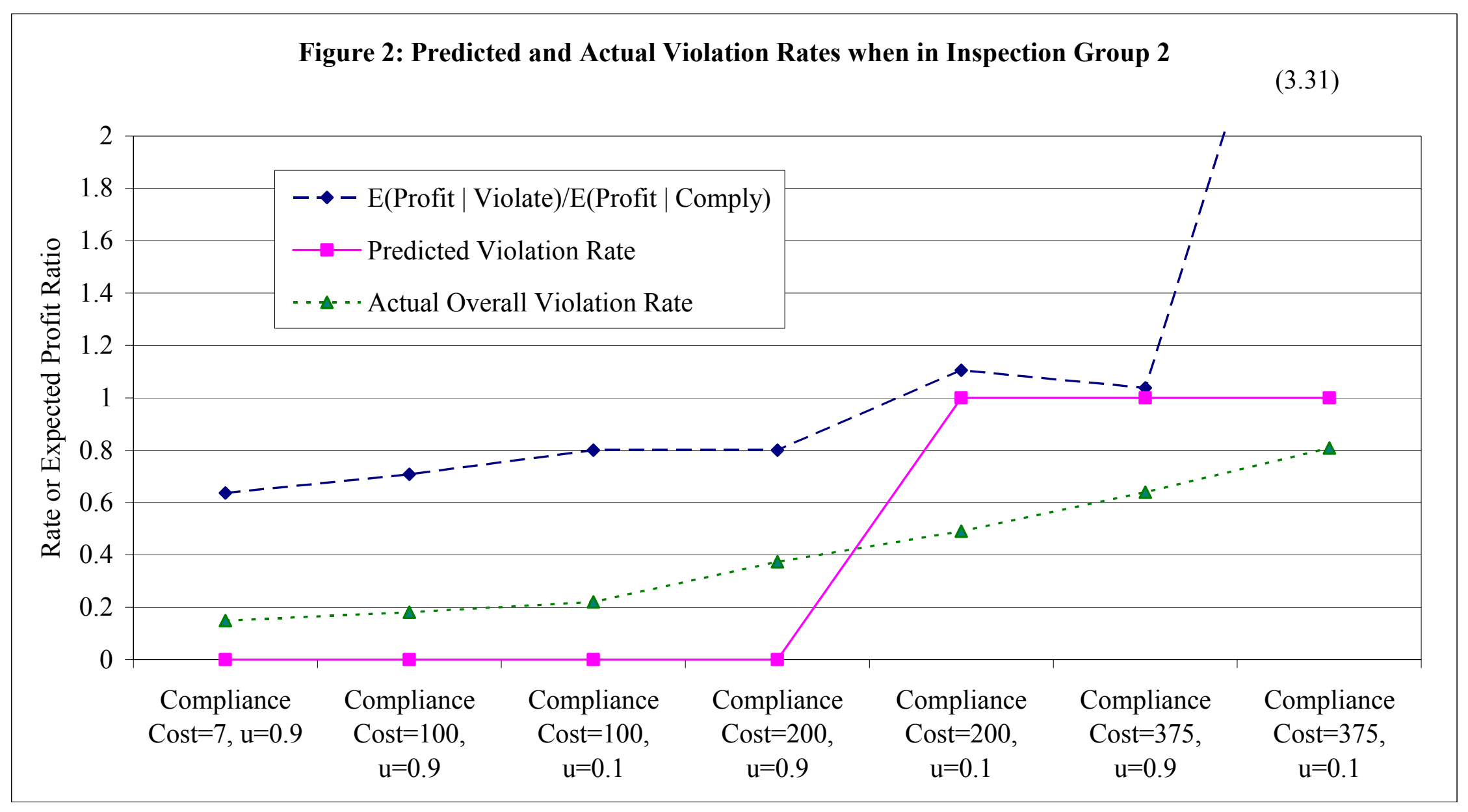


Figure 3: Observed and Predicted Violation Rates (Quantal Choice and Perfectly Optimal Benchmarks) All for $\mu=976$

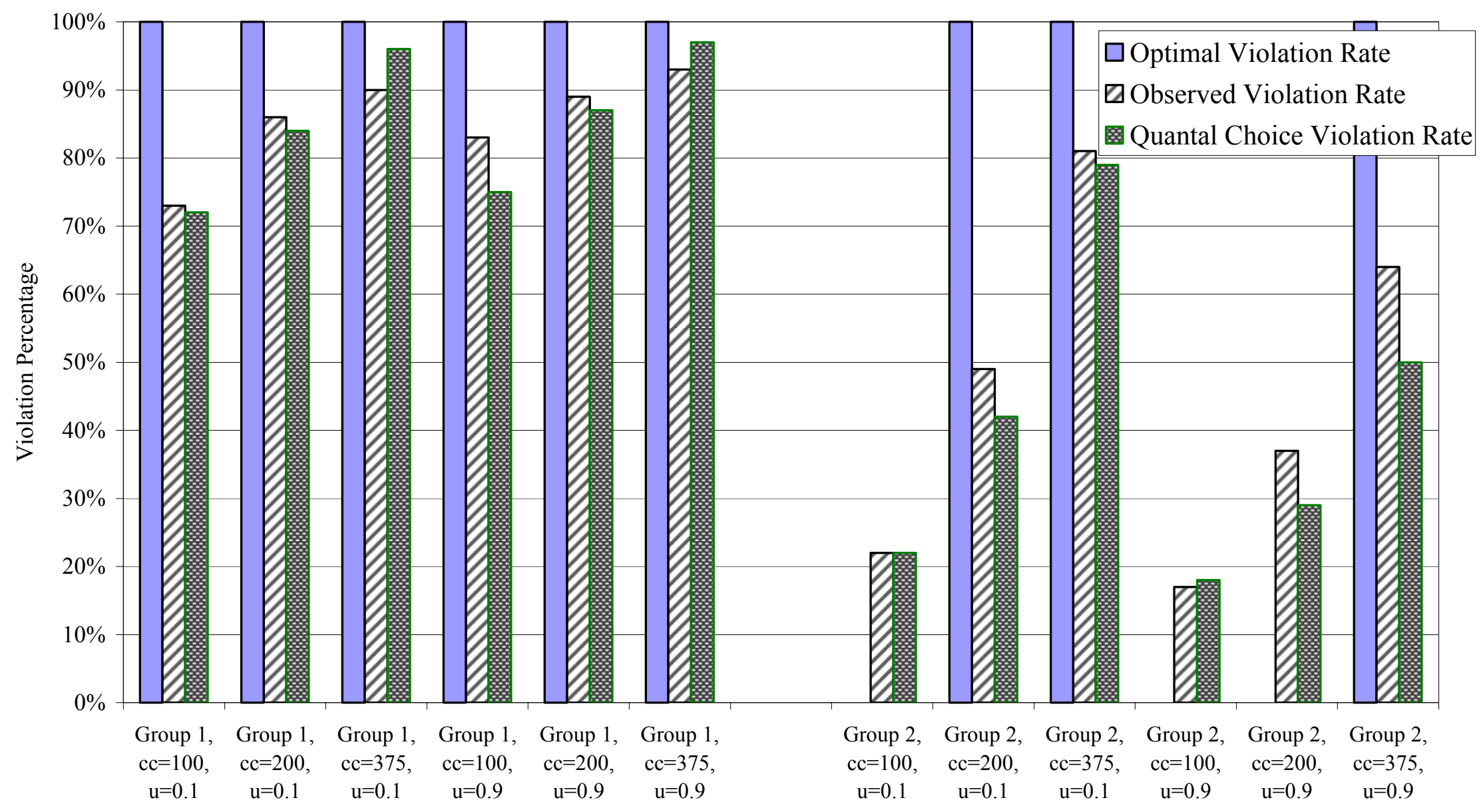




\section{Instructions}

\section{General}

This is an experiment in the economics of decision making. The instructions are simple and if you follow them carefully and make good decisions you will earn money that will be paid to you privately in cash. All earnings on your computer screens are in Experimental Dollars. These Experimental Dollars will be converted to real Dollars at the end of the experiment, at a rate of Experimental Dollars $=1$ real Dollar. Notice that the more Experimental Dollars that you earn, the more cash that you receive at the end of the experiment.

You are going to make a simple decision to either "Comply" or "Violate" in each period. We will conduct a random number of periods in seven separate period sequences. Attached to these instructions you will find a sheet labeled Personal Record Sheet, which will help you keep track of your earnings based on the decisions you make. You are not to reveal this information to anyone. It is your own private information.

\section{Your Decision}

Each period you decide whether to pay your compliance cost. This compliance cost may vary across period sequences, but it remains unchanged for every period within a period sequence. You pay the compliance cost only if you chose Comply. If you choose Violate, your compliance cost is zero. Each period you receive revenue, regardless of what you do. So your earnings each period are determined as follows:

\section{Earnings $=$ Fixed Period Revenue - Compliance Cost (only if you choose to Comply) - Fines Paid (if any).}

Your Fixed Period Revenue does not depend on any actions you take, and does not change throughout the experiment. (In fact, it is already written on your Personal Record Sheet.) You make your compliance decision by filling out an Inspection Report, illustrated in Figure 1, simply by selecting either the Comply or Violate button and then clicking Continue. 


\section{Inspections}

The inspector may or may not "inspect" you to determine if you decided to comply or not. The probability (or, "likelihood") that he inspects you depends on which Inspection Group you are currently in, as shown on the bottom of Figure 1. These probabilities do not change during the entire experiment. If he does not inspect you, then whether or not you decided to comply is irrelevant. None of the numbers shown in Figure 1 change within a period sequence, but the two circled numbers may change when we start a new period sequence.

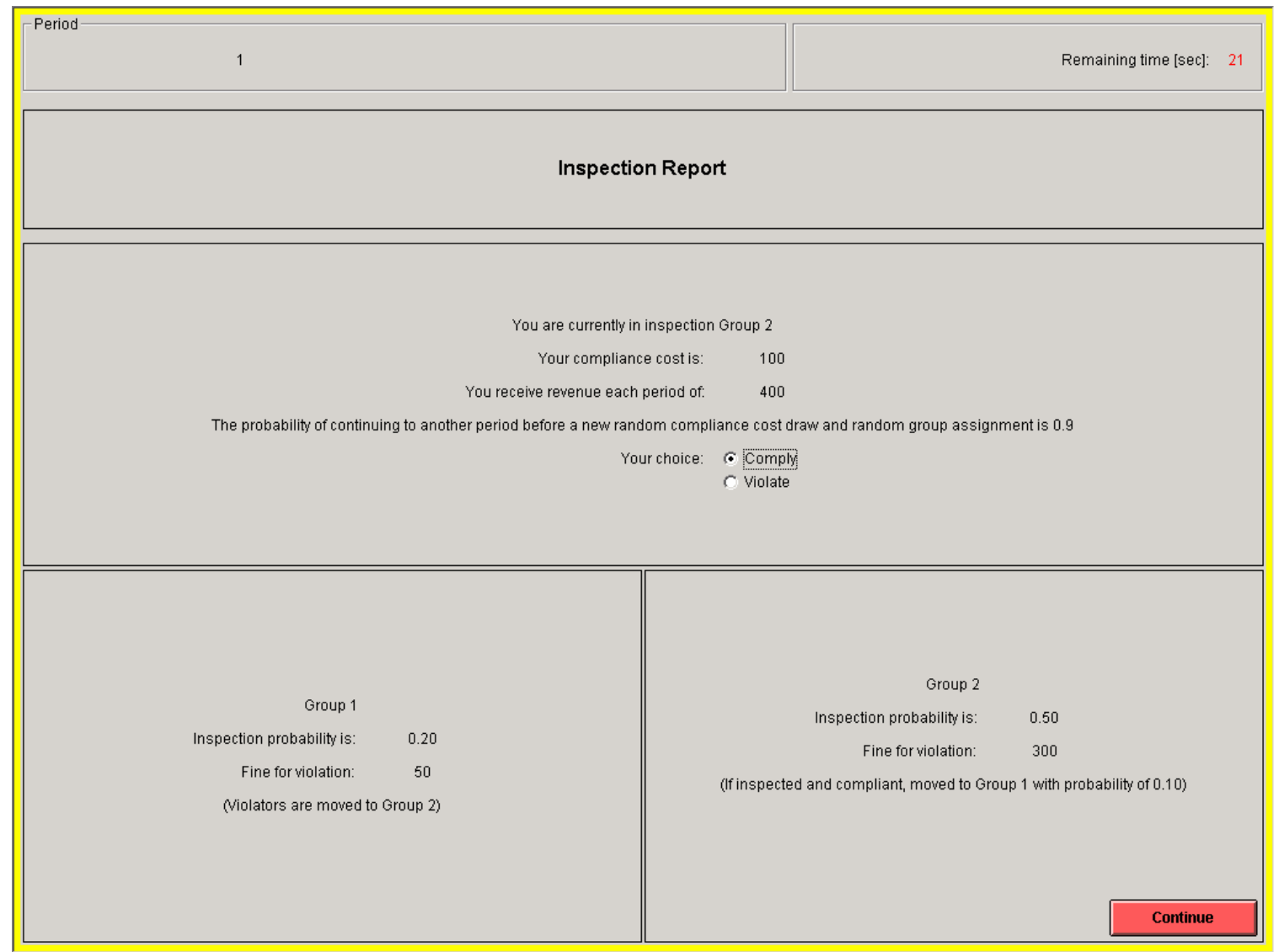

\section{Figure 1}

If he does inspect you, you do not pay a fine if you chose Comply, but you do pay a fine if you chose Violate. The size of the fine depends on which Inspection Group you are currently in, as shown at the bottom of Figure 1. These fines also do not change during the entire experiment. 
If you are in Inspection Group 1 and are inspected and chose to Violate, then you will automatically be moved to Inspection Group 2. If you are in Inspection Group 2 and are inspected and chose to Comply, then you may be moved back into Inspection Group 1. The probability that you would be moved back to Group 1 is shown on the bottom right of your Inspection Report screen, shown in Figure 1. This probability may change in different period sequences.

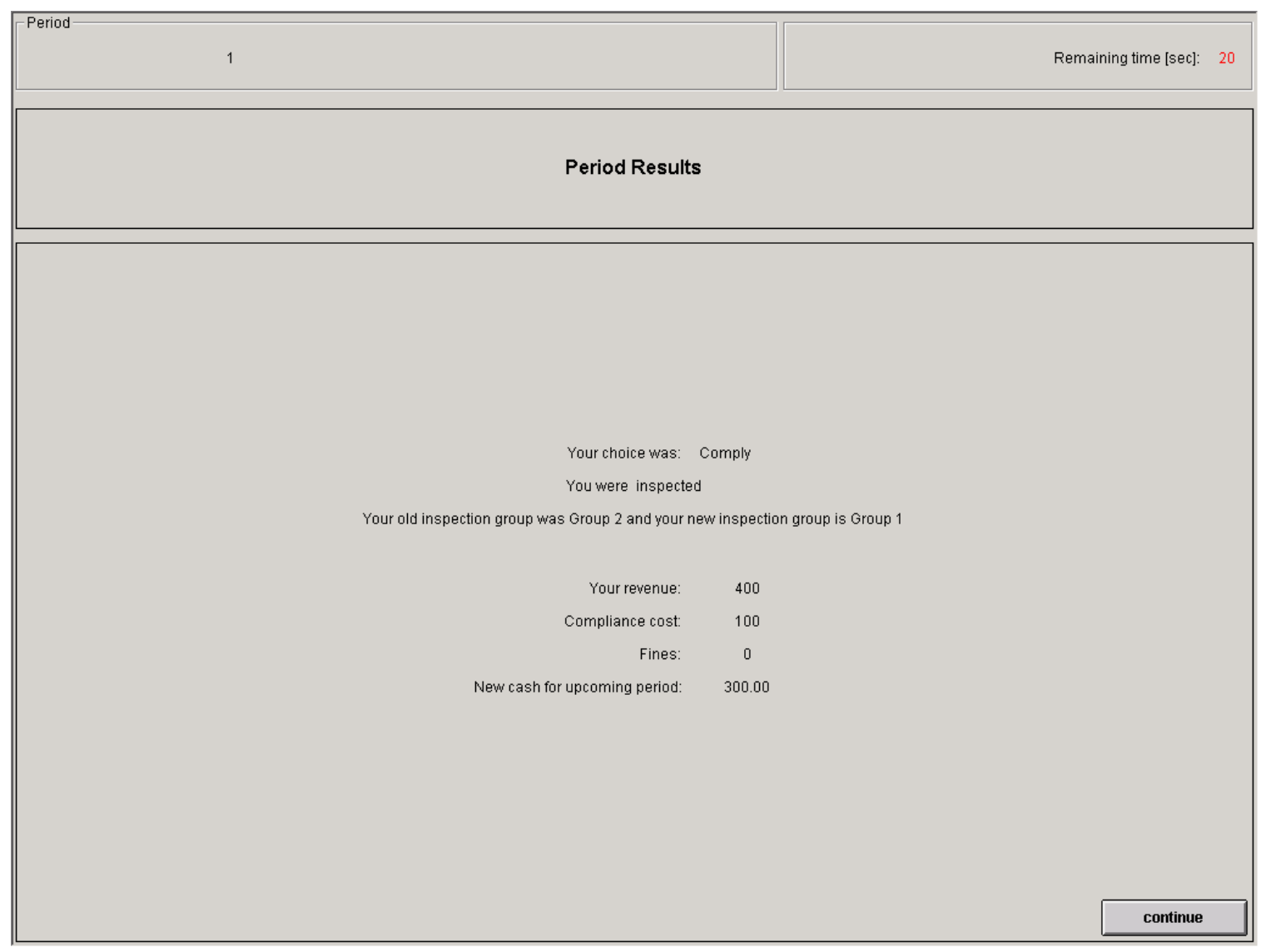

Figure 2

\section{Period Results}

Whether or not you are inspected and a summary of the results from the period are shown on the Period Results screen; Figure 2 presents an example. Your cash holdings are updated for the next period (and remember, these are the cash holdings that get converted into actual dollars at the end of the experiment). You should copy this information onto your Personal Record Sheet at the end of each period, and then click "continue" to begin the next period. 


\section{Starting a New Sequence of Periods}

Remember that which Inspection Group you are in depends on your decisions and whether or not you were inspected. However, each period there is a $10 \%$ ("1 out of 10 ") chance that we will start a new period sequence, with a possibly new compliance cost and a new probability of moving from Group 2 to Group 1 if you were inspected and found in compliance when in Group 2. Whenever we start a new sequence, everyone is randomly assigned into Inspection Groups 1 or 2, regardless of any decisions or inspections that have occurred so far in the experiment. Each period there is a $90 \%$ ("9 out of 10") chance that we will continue in the same period sequence, in which your Inspection Group depends on your previous decisions and whether or not you were inspected. The random "draw" that determines whether we start a new period sequence is independent each period, so it does not depend on how many periods have been conducted so far in a sequence. The experimenter determined the random final period of each sequence before today's experiment. But you will not learn which period of each sequence is randomly chosen to be the last period of that sequence until that last period is completed. We will conduct a total of 7 separate period sequences in today's experiment.

\section{Summary}

- You decide to Comply or Violate each period. You pay a compliance cost if you chose to Comply, and you pay zero compliance cost if you chose to Violate. This compliance cost may vary in different period sequences.

- You may be inspected each period to see if you chose to Comply. If you are not inspected you do not pay a fine. If you were inspected and chose to comply you do not pay a fine. If you were inspected and chose to Violate you pay a fine.

- The likelihood that you are inspected and your fine depends on which Inspection Group you are in.

- You move from Inspection Group 1 to Inspection Group 2 if you were inspected and you chose to Violate. You might move from Inspection Group 2 back to Inspection Group 1 if you were inspected and you chose to Comply, and the chances of making this move may vary in different period sequences.

- Each period there is a $10 \%$ (" 1 out of 10 ") chance that the sequence ends, and at the start of a new period sequence everyone is randomly reassigned into Inspection Groups 1 and 2.

Are there any questions now before we begin the experiment? 